\title{
PROCEDIMENTOS DE PREPARAÇÃO E CARACTERIZAÇÃO DE AMOSTRAS DE PÓ DE ARGILAS
}

\section{Idlla Holanda Pessoa Pio1* ${ }^{*}$, Érico Rodrigues Gomes², Rodolpho Carvalho Leite ${ }^{3}$, Ayrton de Sá Brandim$^{4}$, Laecio Guedes do Nascimento ${ }^{5}$, Lucas Gamaliel Andrade Fialho ${ }^{6}$ and Fernanda da Luz Barbosa ${ }^{7}$}

\author{
1,2,3, 4,6,7Instituto Federal do Piauí - IFPI, Programa de Pós - Graduação em Engenharia de Materiais - PPGEM, \\ Teresina, Piauí, Brasil \\ ${ }^{5}$ Centro universitário Santo Agostinho - UNIFSA, Graduação em Engenharia Civil, Teresina, Piauí, Brasil
}

\section{ARTICLE INFO}

\section{Article History:}

Received $27^{\text {th }}$ March, 2021

Received in revised form

$30^{\text {th }}$ April, 2021

Accepted $17^{\text {th }}$ May, 2021

Published online $26^{\text {th }}$ June, 2021

Key Words:

Preparação de Amostras,

Argilas, Técnicas de Caracterização.

*Corresponding author:

Idlla Holanda Pessoa Pio

\begin{abstract}
A caracterização e preparação de amostras de argilas são muito importantes para o estudo de suas propriedades e obtenção de parâmetros de qualidade para suas melhores aplicações industriais. Nesse sentido, o objetivo deste trabalho foi desenvolver uma revisão bibliográfica acerca da preparação de amostras de argilas para submissão às mais destacadas e usuais técnicas de caracterização. As pesquisas foram realizadas nas bases de dados Google Acadêmico, SciELO, BDTD, Scopus, Science direct e portal de periódicos CAPES, direcionando a abordagem para caracterizações físicas, químicas, mineralógicas e térmicas das argilas, as quais se destacaram as análises de granulométrica a laser, peneiramento e sedimentação, limites de Atterberg por indicações de normas ABNT, grau de humificação por espectroscopia UV-Vis; composição química por FRX; fases minerais constituintes por DRX e por fim análises térmicas de perda de massa e fluxo de calor pelas técnicas de TG e DSC, respectivamente. Os resultados teóricos obtidos foram demonstrados em forma de padrões e modelos esperados para o comportamento das argilas de acordo com a técnica e a preparação utilizadas na sua caracterização. Conclui-se que, embora vastas as técnicas e preparação das amostras, qualificou-se aquelas de maior destaque e usabilidade pelas literaturas estudadas.
\end{abstract}

Copyright (C) 2021, John Mikhail Bahig et al. This is an open access article distributed under the Creative Commons Attribution License, which permits unrestricted use, distribution, and reproduction in any medium, provided the original work is properly cited.

Citation: John Mikhail Bahig, Shady Atef Mansour, Eslam A. Mohamed, Ali A. Ali, Nabel A. Negm and Ismail, A. "Procedimentos de preparação e caracterização de amostras de pó de argilas ", International Journal of Development Research, 11, (06), 47877-47885.

\section{INTRODUCTION}

Essenciais a maioria dos produtos cerâmicos, as argilas são agregados sólidos compostos por um conjunto de minerais chamados de argilominerais (formados por silicatos de $\mathrm{Mg}$ hidratados, $\mathrm{Fe}$ e $\mathrm{Al}$ ) e outros componentes como matéria orgânica, partículas como quartzo, calcita etc., as quais podem ser encontrados na natureza em diferentes composições numa gama de nomenclaturas [1]. Com isso, as argilas são bastante heterogêneas e em relação as características, são dependentes de suas origens geológicas e locais das quais são extraídas [2]. Nesse sentido, com a tamanha variedade de argilas naturais quanto a composição, se fazem muito importante os procedimentos de caracterização e preparação de suas amostras, para assim alcançar melhores aplicações e potenciais tecnológicos a baixos custos e com menos empenhos (a citar o incentivo a sustentabilidade e redução do gasto de energia ou água) [2], [3]. Diante disso, diversos são os países que já priorizam as caracterizações físicas, químicas, mineralógicas e térmicas das argilas nos seus processamentos para uma melhor qualificação de seus produtos [4]. Contudo, as técnicas de caraterização físicas, químicas, mineralógicas e térmicas auxiliam também na obtenção de propriedades mais refinadas aos diversos produtos cerâmicos derivados das argilas, bem como promovendo versatilidade às fábricas, otimização em suas misturas e maior valor agregado à sua produção [3], [4]. Ademais contribuem para evolução de estudos nas áreas de geologia, arqueometria, ciências ambientais e como já citado, setor da indústria, seja no setor de mineração, processamento de alimentos, farmácia e a própria produção de cerâmica [5]. Portanto, este artigo teve como objetivo, desenvolver uma revisão bibliográfica acerca da preparação de amostras de argilas e suas devidas técnicas de caracterização, visando assim um 
norteamento de procedimentos de avaliação das propriedades das argilas para possíveis aplicações industriais, sendo destacadas as técnicas mais práticas e utilizadas.

\section{MATERIAIS E MÉTODOS}

Procedimentos Metodológicos: Esta pesquisa é de caráter bibliográfico e teve como pretensão, abordar análises críticas acerca de publicações científicas, bem como: livros, artigos, anais de congressos, teses, dissertações e outros trabalhos acadêmicos que tiveram especificadas em seus estudos, a preparação de suas amostras de argilas, bem com a apresentação das técnicas realizadas para caracterização dessas amostras, cabendo então a este trabalho, qualificar dentre as encontradas, as mais passíveis de aplicação. Contudo, as bases de dados utilizadas foram: Google Acadêmico, Scientific Electronic Library Online - SciELO, Biblioteca Digital Brasileira de Teses e Dissertações - BDTD, Scopus, Science direct e portal de periódicos CAPES (Coordenação de Aperfeiçoamento de Pessoal de Nível Superior). Por conseguinte, não houve coleta de dados "in situ", ao mesmo que também não se objetivou classificar-se em uma mera transcrição de ideias.

Preparação prévia das amostras: Para a preparação das amostras, essas podem ser extraídas das jazidas por métodos de lavras (mineração) mais comumente a céu aberto ou fornecidas pelas indústrias de cerâmicas que executam tal extração corriqueiramente, seja com o uso de retroescavadeiras ou similares, onde em seguida ocorre o carregamento, transporte e pilhas de estocagem, por conseguinte, o beneficiamento ou tratamento para um devido fim de produção acontece já distante das lavras nas próprias indústrias de transformação [6]. De acordo com uma pesquisa realizada em argilas de três regiões do noroeste de Marrocos, as amostras foram obtidas de uma indústria de cerâmica a partir de uma extração norteada por estudos de identificação do solo. O procedimento se deu inicialmente com a nomeação das amostras, em seguida secagem à $60^{\circ} \mathrm{C}$ por $48 \mathrm{~h}$ para resultar no estado bruto do material e só assim passar por uma trituração e peneiramento a 80 micrômetro $(\mu \mathrm{m})$, em que as frações passadas pela peneira tiveram nova nomeação. Contudo, realizou-se uma purificação concentrando os argilominerais e separou a parcela $<5 \mu \mathrm{m}$ por dispersão da massa de água e deu-se outra nomeação. Desse modo foram analisadas quinze amostras ao total [3]. Paralelamente em outro estudo de caracterização de argilas para produção de cerâmica vermelha no município de Crato - CE, Brasil, as amostras de massas cerâmicas foram extraídas de depósitos locais e divididas em três nomenclaturas para seguida secagem em estufa á $110^{\circ} \mathrm{C}$ por $24 \mathrm{~h}$ e posteriormente passar por processos de trituração e moagem utilizando moinho de bolas. As amostras também passaram por peneiras de numeração inferior à $125 \mu \mathrm{m}$ [7]. Similarmente, em argilas do tipo bentonítica da cidade de Cubati - PB, Brasil, as amostras foram extraídas de uma Fazenda local e também nomeadas para seguida secagem a $60^{\circ} \mathrm{C}$ por $48 \mathrm{~h}$ e sequencialmente o peneiramento em malha de $\mathrm{n}^{\mathrm{o}} 200(0,075$ milímetro (mm)) da ABNT para só então ser expostas ás análises de caracterização [2].

Analogamente, no Sudeste da Tunísia, seis amostras de argilas com $50 \mathrm{~kg} / \mathrm{cada}$, foram extraídas do depósito Aptian Douiret, durante estudo geotécnico, sendo nomeadas de acordo com a origem sedimentar. Estas foram submetidas ao quarteamento, obtendo-se boa parcela amostral. Contudo, após coleta, todas as amostras passaram por secagem a $105^{\circ} \mathrm{C}$ até o alcance do peso constante, seguida de pulverização por $30 \mathrm{~min}$ [8]. Portanto, nota-se que o procedimento para preparação de amostras de argila, segue um determinado padrão após a sua extração, não necessariamente idêntico pois cada estudo possui sua especificidade de acordo com a finalidade que se deseja trabalhar as argilas. $\mathrm{E}$ ao que diz respeito às técnicas de caracterização utilizadas, cada técnica exige uma diferente preparação de amostra, adiante abordadas nesta pesquisa.

Técnicas de Caracterização e preparação das amostras: Em síntese e como brevemente já citado, as técnicas de caracterização dos materiais argilosos podem ser direcionadas de acordo com suas propriedades físicas, químicas, mineralógicas e térmicas, as quais após as análises, podem demonstrar o melhor desempenho da matéria-prima frente às diversas finalidades cerâmicas [8]. Nesse sentido, para as amostras de pó podem ser estudadas as características físicas, atribuídas conforme distribuição do tamanho dos grãos (ou partículas), área de superfície específica, limites de consistência e grau de matéria orgânica total (apenas algumas abordadas); as químicas com determinação da composição elementar da argila, e ao que diz respeito à composição mineralógica e propriedades térmicas, admite-se medições das fases cristalográficas dos minerais e variações de massa/fluxo de calor, respectivamente. [9]. Vale ressaltar, que as análises tecnológicas tal como absorção de água, retração linear, resistência à flexão e porosidade aparente a partir da preparação de corpos de prova secos e queimados, não serão abordadas em função de optar-se por uma pesquisa restrita apenas à uma caracterização do pó das argilas sem simulação de processo industrial [10].

Análises físicas: Admite-se que para realização de C.1.1 à C.1.6 a seguir, as amostras de argila tenham sido preparadas com secagem prévia ao ar para obtenção de umidade higroscópica, bem com promoção de destorroamento cuidadoso (sem danos aos grãos) e homogeneização. Além disso, deve haver separação da amostra para se trabalhar em quantidades representativas e suficientes para todos os ensaios, para isso utiliza-se a técnica de quarteamento, seguida de peneiramento na malha de $2,00 \mathrm{~mm}$, peneira de $\mathrm{n}^{\circ} 10-$ ABNT como procedimento geral [11].

Distribuição do tamanho dos grãos: Uma das características essenciais das argilas se deve à sua granulometria, que pode definir sua fundição ou capacidade refratária (relação com a temperatura de sinterização em caso de preparações industriais). Desse modo, dentre as técnicas que podem ser usadas para a classificação granulométrica das argilas, destacam-se o peneiramento fino e sedimentação descritos pela norma NBR 7181/84 - ABNT e granulometria a laser ou difração de raios laser utilizando aparelhos como o granulômetro dos tipos Cilas 920 LD, Cilas 1064 LD por exemplo (Vale ressaltar que argilas são frações finas compostas por partículas menores $(<)$ que $0,002 \mathrm{~mm}$ ) [2], [12]. Em vista disso, para o peneiramento fino, deve ser tomado $70 \mathrm{~g}$ da parcela de argila passante na $\mathrm{n}^{\circ} 10$ (considerado feito o destorroamento em almofariz sem quebra dos grãos), pesando tal amostra com a sensibilidade de 0,01 gramas (g) e anotando a massa úmida $(\mathrm{Mh})$, em seguida lavar esse material na peneira de $\mathrm{n}^{\mathrm{o}}$ $200(0,075 \mathrm{~mm})$ utilizando água potável sob baixa fluidez. Posteriormente a fração retida nessa última peneira, é seca em estufa à $110^{\circ} \mathrm{C}$ para constância da massa e com auxílio de um agitador mecânico, submeter a amostra às peneiras de 1,$2 ; 0,6 ; 0,42 ; 0,15 \mathrm{e}$ $0,075 \mathrm{~mm}$ para então anotar o peso com sensibilidade de $0,01 \mathrm{~g}$ de todas as frações retidas e acumuladas nas peneiras citadas [13].

Ao que diz respeito à sedimentação, a amostra de $70 \mathrm{~g}$ também separada após peneira de $2 \mathrm{~mm}$, é inserida em um béquer e passada por defloculação com hexametafosfato de sódio em solução [13]. Assim, realizado agitação e descanso por cerca de 12 horas (h), a amostra retida no béquer é removido com bisnaga e então transferida para dispersão com adição de água destilada, o procedimento é repetido e há nova dispersão e transferência da amostra desta vez a uma proveta com traço de 1000 mililitro (ml), que por sua vez é posta em um tanque, agitando-se com bastão de vidro as partículas sobrenadantes em temperatura constante, após período de $24 \mathrm{~h}$, tomase a proveta tapando com a própria mão e promove uma rotação. Por fim, a proveta é posta em uma superfície para sedimentação, executando leituras com ajuda de um densímetro associando ao tempo da sedimentação, após última leitura, é feita lavagem da amostra na peneira de $0,075 \mathrm{~mm}$ [13], [14]. Sobretudo, para o ensaio de difração a laser na identificação do tamanho e distribuição das partículas, utiliza-se um sedimento a granel juntamente ao investigador à laser, onde as amostras devem ser preparadas por dispersão conforme NBR 7181/84, sendo para isso adicionadas à água deionizada (em quantidade específica) contendo alguma substância ou agente dispersante e em seguida ser distribuídas num agitador de alta rotação 
(média de $2000 \mathrm{rpm}$ ) para desagregação concebidas por ondas ultrassônicas [2], [9].

Limite de liquidez ( $L$ L): O limite de liquidez (LL) avalia a resistência da argila ao cisalhamento para um determinado teor de umidade, essa relação é visualizada a partir do números de golpes necessários para que a amostra separada por uma ranhura seja unificada no aparelho Casagrande (Fig. 1), composto por uma base rígida com uma concha fixada a uma manivela manuseada em frequência constante, além de um cinzel [7].

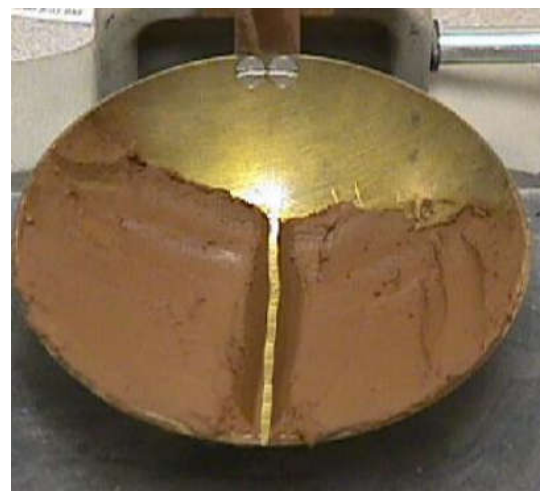

Fig.1. Exemplo de uma amostra de argila na concha do aparelho Casagrande [14]

Contudo, a amostra a ser utilizada nesse ensaio deve ser a fração que passa na peneira de $\mathrm{n}^{\circ} 40$ - ABNT $(0,42 \mathrm{~mm})$ (de forma a se trabalhar com $200 \mathrm{~g}$ ), formando uma pasta homogênea com água destilada em um recipiente de porcelana (até um certo grau de umidade) para em seguida ser inserida na concha citada, ocupando-a em 2/3 [15]. Assim, com auxílio do cinzel, deve ser promovida uma ligeira abertura nessa pasta para então golpear a concha contra a base através da manivela até que a pasta dividida se unifique [14], [15]. No momento em que se une, o ensaio é concluído tomando-se uma porção da amostra que se uniu para ser pesada e em seguida levada em estufa para o cálculo da umidade e também deve ser feito o registro do número de golpes que uniu a pasta. O procedimento é repetido com outros graus de umidades [15].

Limite de plasticidade (LP): O limite de plasticidade (LP) indica o estado plástico (capacidade de moldagem) da argila para o estado sólido a uma determinada variação no grau de umidade [7]. Porquanto, para realização desse ensaio, a amostra também deve ser resultado da peneira de $\mathrm{n}^{\circ} 40$ revolvida com água destilada no recipiente de porcelana até obtenção de homogeneidade e consistência plástica, com isso é extraída $10 \mathrm{~g}$ da amostra para gerar uma bola e submetê-la a rolagem sobre uma placa de vidro utilizando a pressão das mãos de modo a gerar um cilindro, se esse se romper antes de alcançar $3 \mathrm{~mm}$ de diâmetro, deve ser feita nova homogeneização com água destilada, caso alcance e tenha o comprimento de $100 \mathrm{~mm}$, tomar a amostra para pesagem e em seguida secagem em estufa para estabelecimento da umidade, o procedimento deve ser repetido para no mínimo três teores de umidade [16].

Índice de plasticidade (IP): A plasticidade das argilas é uma das características de maior relevância para definição de suas moldagens e aplicação [17].

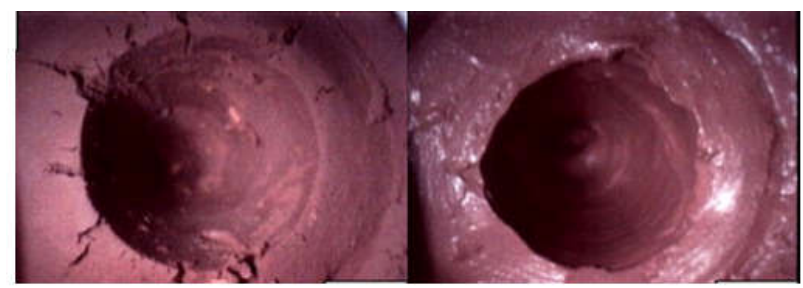

Fig. 2 Amostra de argila e limites de Atterberg, adaptado de [17]
Nesse sentido, ela pode ser determinada pelo índice de plasticidade (IP) pela diferença entre o limite de liquidez (LL) e o limite de plasticidade (LP) (limites de Atterberg) [16], dada por (1) (resultando em percentual), abaixo:

$I P=L L-L P$

Além disso, existem outras técnicas de determinar a plasticidade das argilas, seja por indentação instrumental ou o método de Pfefferkorn, esse último por ser mais trabalhoso e demorado, optou-se por não explicitar a preparação das amostras para realização de seu ensaio [17], [18]. Desse modo, para a indentação separa-se $700 \mathrm{~g}$ de amostra e passa por uma moagem, a fração suspensa é seca em estufa e a parcela granular deve passar por desagregação e peneiramento numa peneira de 500 mesh (padrão American Society for Testing and Materials - ASTM). Em seguida, é acrescida ao pó seco, água em cerca de $25 \%$ para sequente homogeneização em agitador mecânico e uniformidade [17]. O ensaio é condicionado por uma resistência imposta pela amostra de argila ao sofrer ação de uma força de indentação (punção, em quilograma), e a plasticidade é obtida com auxílio de um display digital (sensibilidade de $0,01 \mathrm{~mm}$ ) de acordo com a maior força aplicada associada ao teor de umidade da amostra. Se o indício da perfuração não demonstrar fissuração ou fluxo plástico, o experimento é validado e a força que se mostra no dispositivo (Penetrômetro ou Plasticímetro de indentação) equivale a plasticidade [17], [19]. Por fim, após o ensaio supracitado, pode se determinar o índice de plasticidade. Isso é demonstrado pela Fig. 2, que de um lado evidencia a ausência de plasticidade (falta umidade) e do outro ausência de consistência (umidade excessiva), que definem os limites de Atterberg [17].

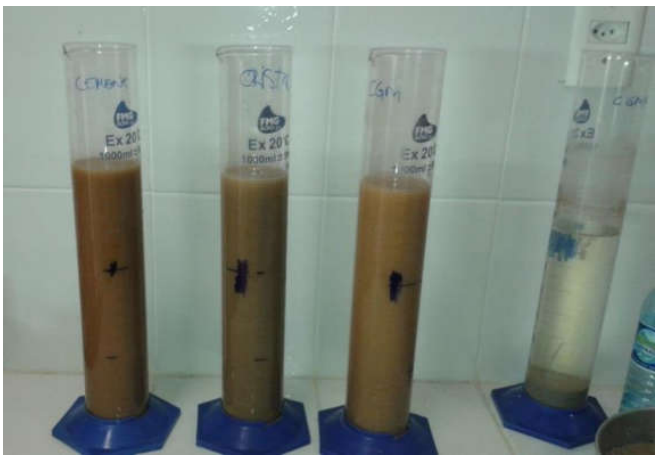

Fig. 3. Demonstração de uma preparação de amostras de argila em provetas para realização do ensaio de DRX [7]

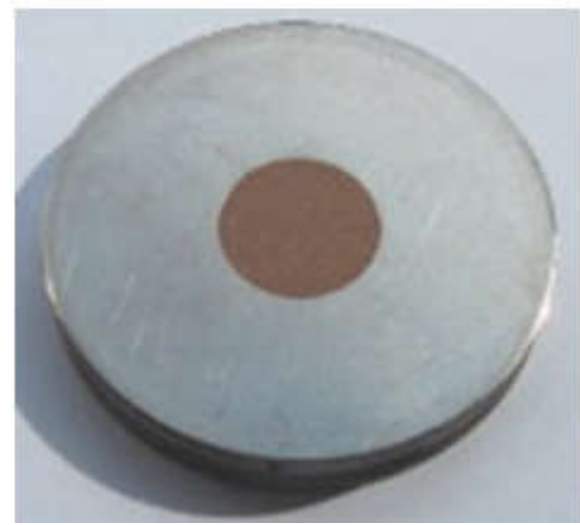

Fig. 4. Demonstração de uma amostra de pó de argila sobre uma placa de vidro para submissão ao DRX [33].

Índice de consistência (IC): Do mesmo modo, se deve constatar o índice de Consistência (IC) das argilas, pois essa característica mostra sua capacidade de deformação, podendo se classificar desde moles até duras [20]. Com isso, é possível conhecer o teor de umidade da argila no intervalo de sua utilidade para aplicação, em outros termos, umidade ideal entre o limite de liquidez e o de plasticidade. 


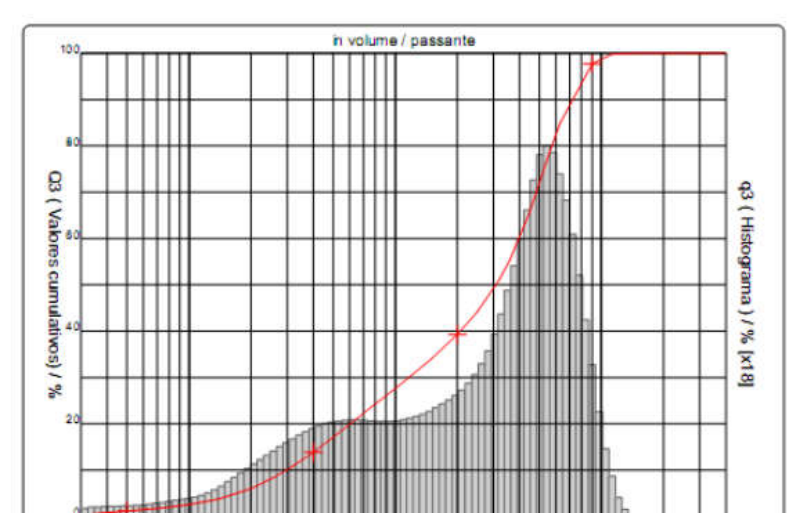

Fig.7 Modelo de diagrama resultante de granulômetro a laser [10]

Assim, pode ser obtido de forma quantitativa (e cada consistência é determinada para argilas no estado saturado) utilizando (2) que faz uma relação entre o Limite de liquidez (LL), teor de umidade do solo natural (w) e o índice de plasticidade (IP) [7], demonstrada a seguir:

$$
I C=\frac{(L L-w)}{I P}
$$

A umidade natural da argila é determinada tomando-se cerca de $30 \mathrm{~g}$ (parcela $<2 \mathrm{~mm}$ ), realização de destorroamento evitando a perda da umidade, inserção em cápsulas metálicas e pesagem do conjunto, em seguida levando-as à estufa para secagem durante um intervalo de 16 a $24 \mathrm{~h}$ (variando se a amostra estiver muito úmida), após retirar da estufa se faz uma nova pesagem, devendo estabelecer três teores de umidade por amostra. A obtenção do teor de umidade é dada pela divisão da massa de água em composição à amostra pela massa seca após estufa, em porcentual [11].

Matéria orgânica/grau de humificação: Para determinação da matéria orgânica (composta em sua maior parte por carbono orgânico (COT)) presente nas argilas, são estabelecidas por exemplo, técnicas de combustão úmida como o Walkley-Black (que gera contaminação laboratorial por cromo) e métodos alternativos de maior destaque como o loss-on-ignition (LOI)/Perda por Ignição, Espectroscopia Ultravioleta - visível (UV-Vis), Espectroscopia de absorção na região Infravermelho (IV) e Ressonância Nuclear Magnética (RMN), todos com o intuito de fornecer informações sobre a composição e origem da Substância Húmica $(\mathrm{SH})$ (será abordado a preparação de amostras apenas para as técnicas de espectrometria) [21], [22], [23], [24]. A matéria orgânica nas argilas é composta em sua maior parte por SH (agregadas também ao COT), que possui em sua composição: ácidos húmicos $(\mathrm{AH})$, ácidos fúlvicos $(\mathrm{AF})$ e humina (HUM), esses são constatados por método de solubilidade em meios ácidos ou básicos [25]. Assim, para submissão à técnicas de espectroscopia como a UVVis por exemplo, as amostras de argila devem passar por processos de extração, fracionamento e purificação das SHs [26]. Conforme o método padrão da International Humic Substances Society (IHSS), a preparação inclui extração por agitação de $4 \mathrm{~h}$ utilizando solução de 0,1 mol.L-1 de hidróxido de sódio $(\mathrm{NaOH})$ em temperatura ambiente e na proporção de 1:10 (argila em massa:solvente em volume), seguida de: purificação usando ácido fluorídrico (HF); preenchimento do sobrenadante formado com a acidificação do meio alcalino por resina DAX-8; diálise contra água em membrana e por fim secagem por liofilização [24], [26]. Para maior eficiência de purificação sobre às impurezas inorgânicas presentes nas SHs, pode repetir dissoluções e precipitações alterando o potencial hidrogeniônico $(\mathrm{pH})$ da solução [27]. A Espectroscopia UV-Vis mensura o quanto uma amostra ou material consegue absorver de luz por moléculas em cada comprimento de onda das regiões UV e do visível no espectro eletromagnético [28]. Esse ensaio se norteia por irradiação e excitação de elétrons para orbitais de maior energia e pode ser realizado com espectrofotômetros de diversos modelos, unidos à computadores para visualização dos espectros em faixas que variam de 200 a 380 nanômetro (nm) (ultravioleta) e de 380 a $800 \mathrm{~nm}$ (visível) [26], [29]. Com isso, dispõe de dados sobre o grau, composição e até origem das SHs. Dentre os principais parâmetros está a relação de E4/E6 (absorbância (Abs) a 465 nm/absorbância (Abs) a $665 \mathrm{~nm}$ ), que em caso de baixa razão, indica maior humificação e condensação da amostra, já em caso de alta, sugerem menores. O coeficiente $\Delta \operatorname{logK}(\log$ Abs400nm - log Abs600nm) também é importante para qualificação das informações [27], [29].

Análise Mineralógica: Para a investigação mineralógica dos argilominerais intrínsecos às argilas, destaca-se a técnica de Difração de Raios X (DRX), a qual se norteia pelos planos cristalinos dos minerais, associado ao fenômeno da difração em fase dos raios-X após emissão aos planos cristalinos de acordo com determinado ângulo, isso sem modificar o comprimento de onda. Com isso, a medida que a emissão de uma fonte dos raios- $\mathrm{X}$ altera a angulação do feixe, a organização dos átomos nos planos cristalinos dos minerais originam reflexões, que por sua vez são recebidas por um detector e podem ser visualizadas em um gráfico rotulado de difratograma, que demonstra a conexão entre amplitude da difração dos raios incididos e o ângulo do feixe emitido pela radiação, onde também se demonstra um arquétipo único para todo mineral [5], [30]. Assim, o reconhecimento dos componentes cristalinos de um determinado material (nesse caso as argilas), pode ser obtido por uma correlação entre os reflexos (picos apresentados no difratograma) com a identidade que cada mineral é capaz difratar [30]. Tal difração ou o espalhamento do feixe da radiação sobre a superfície do cristal, é baseada na Lei de Bragg demonstrada logo abaixo por (3), que relaciona o ângulo de ocorrência da difração e a distância entre os planos que lhe dão origem (específicos para cada mineral). Contudo, muitos são os motivos de utilizar o DRX, incluindo facilidade e agilidade do procedimento, natureza não destrutiva e segurança quanto aos resultados obtidos [5].

$n \lambda=2 d \operatorname{sen} \theta$

$\mathrm{n}$ : número inteiro

$\lambda$ : comprimento de onda dos raios $\mathrm{X}$ incidentes

d: distância interplanar

$\theta$ : ângulo de difração

Para preparação da amostra à essa técnica, pode ser utilizado o método do pó, em que são separadas $50 \mathrm{~g}$ da fração de argila seca pulverizada em moinho ou almofariz de ágata, resultando em um pó fino e homogêneo (inferior a $0,075 \mathrm{~mm}$ ), passo importante para deixar os cristais orientados em todas as direções cabíveis, permitindo a atuação da lei de Bragg com os espalhamentos interplanares [31]. Em seguida, a amostra é inserida e suspensa em um tubo de centrifugação contendo água destilada (entre 40 e $250 \mathrm{ml}$ dependendo do tubo e quantidade de amostra utilizadas), posteriormente um volume de hidróxido de sódio $(\mathrm{NaOH})$ ou de amônio $(\mathrm{NH} 4 \mathrm{OH})$ podem ser inseridos para haver agitação e maior desagregação dos finos. Desse modo, o procedimento continua com transferência da amostra para proveta com mais água destilada (Fig. 3) seguida de centrifugação à alta rotação ou agitação manual intensa, visando assim que uma parte da amostra se deposite no fundo e as frações mais finas fiquem suspensas (por decantação lenta) [7], [30], [32].

Em continuidade, após curto período de descanso, uma porção do sobrenadante e material do fundo são extraídos com auxílio de pipeta, e só então dispostos na forma de uma fina película sobre uma lâmina plana de vidro (Fig. 4), onde após secagem em estufa, será exposto a um feixe de raios-X em amplo intervalo de ângulos incidentes a uma certa velocidade (geralmente de 1\%min) [7], [30],[32]. Contudo, muitos minerais são classificados simples por seus picos ser facilmente detectáveis e apenas uma reflexão principal ser suficiente para identificá-los. Porém, para uma maior certificação na identificação, as amostras após o procedimento supracitado, ainda podem passar por um tratamento de solvatação utilizando o Etilenoglicol (EG) e ainda um tratamento térmico, aquecendo a lâmina padrão numa mufla em temperatura entre 500 e $550{ }^{\circ} \mathrm{C}$ por período de 2 a $4 \mathrm{~h}$, tal procedimento conduz a uma maior distância entre os planos, sendo possível uma melhor distinção entre os minerais [5], [9]. Diante disso, o DRX pode ser executado utilizando 
um difratômetro, dentre eles pode ser citado o Philips X'Pert PRO que trabalha com radiações $\mathrm{CuK} \alpha(1,5418 \hat{\mathrm{A}})$, atuando nas amostras de sedimentos em pó ou a granel nas lâminas de vidro, submetidas a tratamento com solvatação por EG e aquecimento [9]. Em suma, a análise de dados pode ser tratada por softwares como o X'Pert HighScore Plus e PDF-4 e o DIFRAC mais EVA, em que se pode obter o cálculo dos parâmetros dos perfis, bem como altura e área dos picos, posição da linha e outros fatores determinantes para os percentuais mineralógicos das argilas (atribuindo-se apenas uma incerteza de $\pm 5 \%$ ) [8], [9].

Análises químicas: Adiante, seguindo à caracterização das argilas, também se faz necessário análises acerca de seus componentes químicos, os quais são apontados através de óxidos (quando elementos com número atômico maior que o do oxigênio $(\mathrm{O} 2)$ ) e traços (quando menores). Para tanto, as técnicas mais utilizadas são Espectroscopia de absorção atômica (EAA) e Espectrometria de fluorescência de raios-x (FRX) [32], [34]. Definido por caráter não destrutivo, analítico, de rapidez e precisão nas determinações, o método de FRX apresenta muito destaque quanto às informações quantitativas e qualitativas da composição química das argilas [7],[32]. Sendo norteado pela detecção de linhas características ou raios-X específicos, emitidos por cada elemento químico da amostra a medida que essa sofre irradiação (em forma de feixe de radiação primária) gerada por: tubo de raio-X, indução por partícula ou outros [31]. Com tal irradiação, os elétrons dos elementos são excitados e assim expelidos das camadas eletrônicas mais internas, formando então as lacunas que acabam sendo preenchidas por elétrons de camadas mais externas para haver estabilidade do átomo, nesse processo acontece uma diferença de energia (DE) em função do envolvimento dos níveis, por sua vez, típicos de cada elemento químico, assim como as radiações expelidas de toda transição. Portanto, pode ser determinado o elemento e sua concentração de acordo com a anergia de radiação emitida e e sua intensidade, respectivamente [32],[35].

Em síntese, após o procedimento de desagregação por moagem e peneiramento (partículas $<0,044 \mathrm{~mm}$ ), as amostras submetidas ao FRX são preparadas em forma de pastilhas por meio de moldagem e prensagem com molde tipo copo de alumínio ou anel de aço (Fig. 5) em prensa espectrométrica, geralmente submetendo uma força de 10 a 30 toneladas (t) [35]-[37]. Quanto menos características auto ligantes tiver o pó, maior deverá ser a pressão exercida, e se ainda assim não for possível obtenção da pastilha, são usados agentes aglutinantes de ligação, devendo esses ser estáveis frente a vácuo e irradiação e não possuir contaminação (os mais indicados são aqueles à base de celulose de cera) [35].

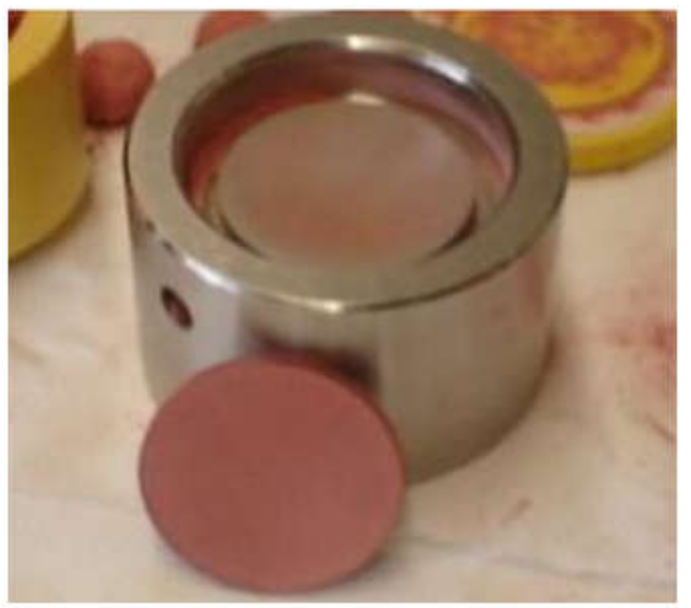

Fig. 5. Modelo de uma pastilha de argila para submissão ao FRX e anel de aço [35]

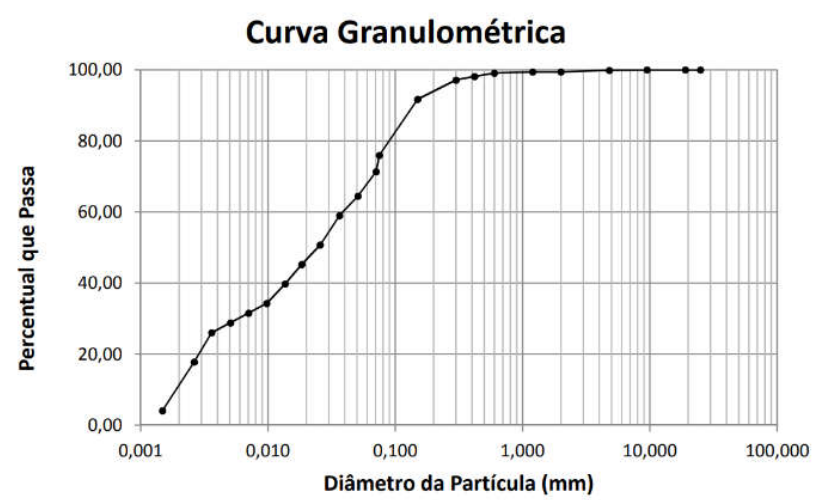

Fig. 6. Modelo de diagrama resultante da análise granulométrica [10].

Em caso de utilização do agente de ligação, as pastilhas podem ser confeccionadas de duas formas: apenas com a mistura da amostra moída junto à cera (em proporções dependentes do estado do pó, usualmente sendo $7 \mathrm{~g}$ de material para $1,4 \mathrm{~g}$ de cera) e submissão à secagem em estufa a $110{ }^{\circ} \mathrm{C}$ por $24 \mathrm{~h}$ seguida de resfriamento em dessecador e assim encaminhadas ao FRX; e/ou pelo método de fundição com mistura da amostra moída ao metaborato e tetraborato de lítio, havendo a calcinação em mufla (cerca de $1000^{\circ} \mathrm{C}$ ) por alguns minutos, promovendo assim formação de discos e análise de perda ao fogo (PF), essa última auxilia na leitura dos óxidos. Vale ressaltar que as dimensões das pastilhas depende da fôrma contida na prensa, podendo ter em torno de $18 \mathrm{~mm}$ de diâmetro [12], [32], [36].

Por conseguinte, a leitura das pastilhas podem ser feitas pelos instrumentos analíticos do FRX, os mais utilizados são: fluorescência de dispersão em comprimentos de onda (WDFRX) e fluorescência de raios-X por dispersão de energia (EDFRX) com suas sub variâncias: fluorescência de raios $X$ por reflexão total (TFRX) e micro fluorescência de raios X ( $\mu$-FRX) [32], [35]. Contudo, a que se fez mais utilizada foi a EDFRX através do espectrômetro de fluorescência de raios-X à vácuo, modelo Philips/Panalytical PW 2400 com tubo de raio X [9], [35], [36], [39].

Análises térmicas: As análises térmicas determinam o comportamento das argilas quando submetidas ao calor em um ciclo sob controle, que se reflete em alterações físicas e químicas tais como dilatação e retração, que podem ser controladas dependendo da composição da argila ao que diz respeito os argilominerais [40]. Assim, tais análises podem identificar características como: variação de massa, estabilidade térmica, calores específicos e de transição, diagrama de fases mineralógicas, entre outras [7], [41]. Dentre as mais utilizadas estão a termogravimétrica (TG), análise térmica diferencial (DTA), calorimetria exploratória diferencial (DSC), análise dilatométrica (DIL) e análise termomecânica (TMA) [42].

Com isso, serão abordadas a TG e DSC que fornecem informações necessárias à fabricação de produtos cerâmicos por exemplo, já que indicam os intervalos de temperatura em que acontece alteração da massa e os processos de variação de energia através de alterações endotérmicas e exotérmicas frente a mudanças na aplicação da temperatura, além de que também auxiliam na determinação das fases mineralógicas presentes e sua quantificação [7], [43]. Na TG, a massa da amostra é verificada conforme aumento da temperatura (cuidadosamente controlado) associado a uma micro balança de precisão que anota e quantifica todo ganho ou perda de massa, já na DSC são registradas as mudanças na entalpia ou energia intrínseca de acordo com as características dos componentes da amostra [43].

Para a realização da TG e DSC são tomadas poucas $\mathrm{mg}$ até $\mathrm{g}$ da amostra (a quantidade é específica ao equipamento escolhido para análise) de argila na forma de pó seco (resultado da moagem e peneiramento na malha 200 mesh), para em seguida submetê-las ao aquecimento em forno controlado e preciso, observando e registrando qualquer mudança de acordo com a temperatura [7], [40]. Os 
equipamentos passíveis de utilização são Shimadzu TGA-50 para TG e Shimadzu DSC-50 para DSC, os quais utilizam $30 \mathrm{mg}$ de amostra em cadinho de alumina (porta amostra) a uma taxa de aquecimento geralmente de $10^{\circ} \mathrm{C} / \mathrm{min}$ e atmosfera de ar sintético (geralmente gás inerte como Nitrogênio (N2) em fluxos de $20 \mathrm{ml} / \mathrm{min}, 50 \mathrm{ml} / \mathrm{min}$, $100 \mathrm{ml} / \mathrm{min}$ e etc. [7], [40], [42], [44], [45]. A variação da temperatura também é condicionada pelo equipamento, as mais encontradas variaram de 25 até $1000{ }^{\circ} \mathrm{C}$ para TG e até $500{ }^{\circ} \mathrm{C}$ para DSC [7], [41].

\section{RESULTADOS TEÓRICOS E DISCUSSÃO}

\section{Análises físicas}

Distribuição do tamanho das partículas: Os resultados da análise do tamanho das partículas realizada por peneiramento podem ser visualizados graficamente por meio de uma curva. No eixo das abscissas se encontram os diâmetros das partículas (escala logarítmica) e no eixo das ordenadas dispõem os percentuais das partículas passantes nas peneiras [13]. As frações granulométricas correspondentes à argila são aquelas com diâmetro menor que 0,002 $\mathrm{mm}$; já silte (muito presentes nas argilas) se enquadram entre $0,002 \mathrm{e}$ $0,06 \mathrm{~mm}$; areia fina entre 0,06 e $0,2 \mathrm{~mm}$ e areia grossa se encontram entre 0,2 e $2 \mathrm{~mm}$ [20]. A Fig. 6 abaixo mostra um modelo do diagrama descrito com uma amostra de argila enquadrada em $80 \%$ de argila e silte e $20 \%$ na faixa de argilas finas e médias [10]. Abaixo (Fig. 7) é mostrado um modelo do diagrama resultante de um granulômetro a laser realizado em argilas passantes em uma peneira de $n^{\circ} 80$ (ABNT). Desta vez, a escala dos diâmetros se apresentam em $\mu \mathrm{m}$ [10]. A partir dos diagramas acima e consequente distribuição das partículas, é possível ainda classificar as argilas de acordo com sua textura, sendo elas: muito argilosas (quando contém mais de $60 \%$ de argila), argila, argilo-arenosa, argilo-siltosa e muitas outras passíveis de visualização pelo Triângulo de classificação textural de solos (de acordo com percentuais dos constituintes), logo abaixo (Fig. 8). Vale ressaltar que quando demonstradas, as amostras se enquadram em pontos marcados dentro do triângulo [46].

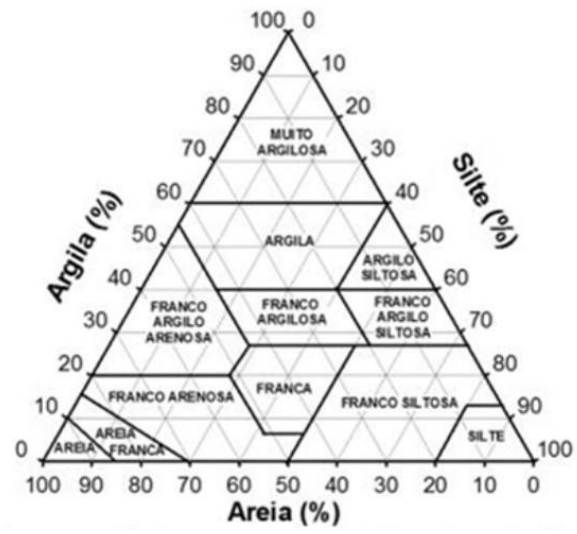

Fig. 8 Modelo de triângulo de classificação textural dos solos [46]

Limite de liquidez ( $L L$ ): Para interpretação do LL, é confeccionado um gráfico (Fig. 9), no qual os eixos das ordenadas (escala logarítmica) destacam o número de golpes para os correspondentes resultados dos teores de umidade qualificados no eixo das abscissas (escala aritmética). Tais pontos originam uma reta, onde o resultado do LL é alcançado pelo teor de umidade correspondente a 25 golpes, que deve ser dada em porcentagem e aproximada ao número inteiro mais próximo. Se na amostra não for possível obter uma abertura de ranhura ou fechamento com mais de 25 golpes, se diz que essa não apresenta LL [15].

Limite de Plasticidade (LP): Os valores de LP são considerados válidos quando: ao menos três dos valores resultantes de umidade, não se diferenciam da respectiva média para mais ou para menos de $5 \%$.

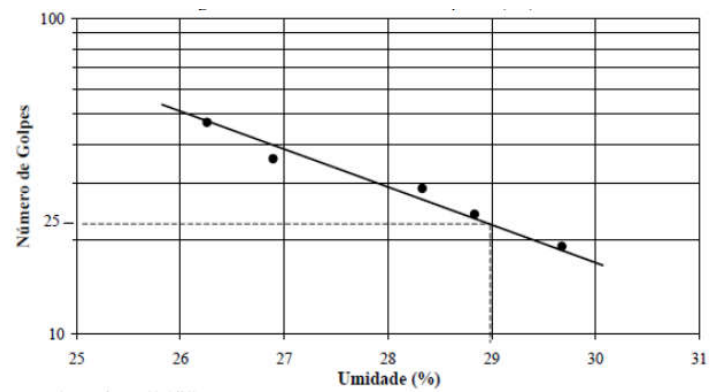

Fig. 9 Modelo de um gráfico de LL [15].

Assim, o resultado final é obtido pela média dos três valores de umidade considerados e também deve ser dado em porcentagem com arredondamento para o número inteiro mais próximo (se na realização do ensaio, não for atingido o cilindro com $3 \mathrm{~mm}$ de diâmetro, se diz que a amostra não apresenta LP) [16].

Quadro 1. Classificação das argilas quanto a sua consistência [47]

\begin{tabular}{ll}
\hline Muito moles & IC $<0$ \\
\hline Moles & $0<\mathrm{IC}<0,50$ \\
Médias & $0,50<\mathrm{IC}<0,75$ \\
Rijas & $0,75<$ IC $<1,00$ \\
Duras & IC $>1,00$ \\
\hline
\end{tabular}

4 indice de plasticidade (IP): Como já citado anteriormente, o resultado do IP é dado por (1), também em porcentagem e segundo uma projeção definida por Jenkins citado por Ref. [47], a classificação da plasticidade segue em: fracamente plástico se o resultado estiver entre $1 \leq \mathrm{IP} \geq 7$; mediamente plástico se $7<\mathrm{IP} \geq$ 15 e altamente plástico se IP $>15$.

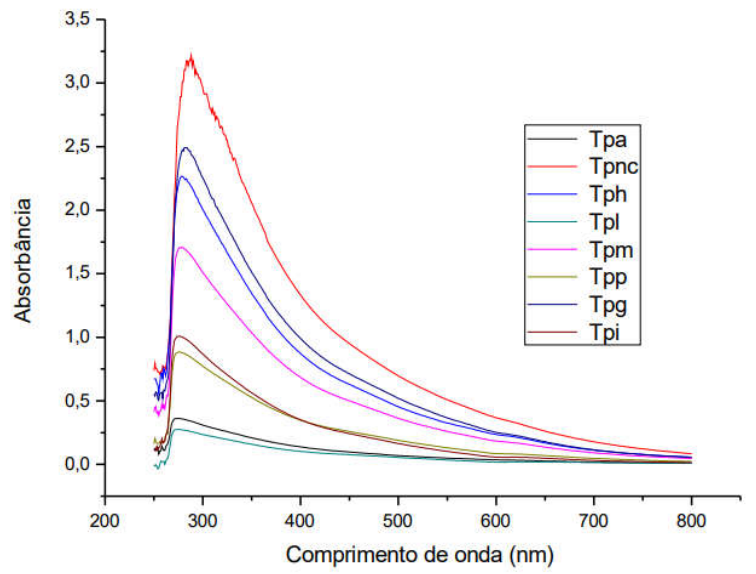

Fig. 10. Modelo de um gráfico de Espectros de UV-VIS de ácidos húmicos extraídos em oito amostras [29]

5 indice de Consistência (IC): A consistência das argilas foi demonstrada por (2) e de acordo com seu resultado, o IC pode classificar as argilas em: muito moles (vazas), moles, médias, rijas e duras (Quadro 1) [47]. Em suma, as argilas muito moles se encontram em condições líquidas, já as argilas moles, médias e rijas se apresentam em condições plásticas e por fim as duras em semissólidas [7], [47].

6 Grau de humificação por UV-vis: Os resultados da técnica de UVvis destacada para os valores qualitativos de matéria orgânica ou grau de humificação, podem ser visualizados em um gráfico de comprimento de ondas de absorção que interage com a intensidade com que essa se dá, seja em absorbância ou transmitância para então contemplação dos espectros [48]. O índice de humificação ou o valor de E4/E6 está vinculado à aromaticidade e nível de condensação da cadeia de Carbonos aromáticos dos $\mathrm{AH}$ (geralmente predominantes), 


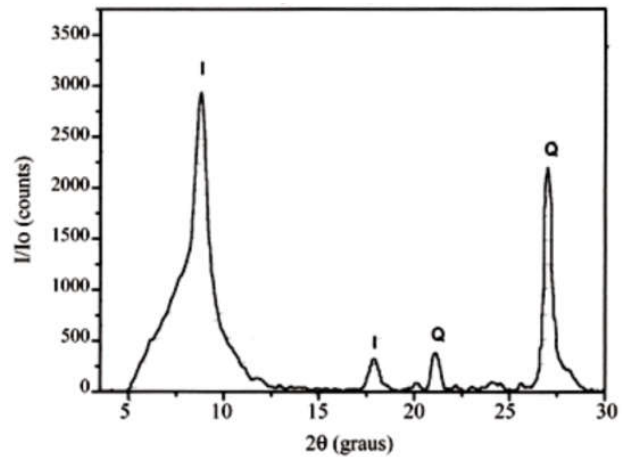

Fig. 11 Modelo de difratograma quantitativo dos minerais constituintes: ilita (I) e quartzo (Q) de uma amostra de argila do estudo em questão [5].

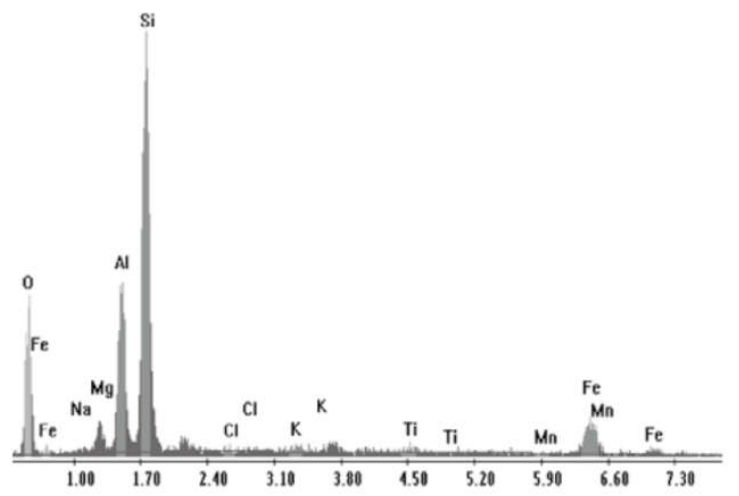

Fig. 12. Modelo de espectros de raios $X$ por energia dispersiva (EDFRX) em uma amostra de argila bentonítica com partículas entre 65-100 mesh [52]

comumente esse valor é menor que 5 [49]. Desse modo, os resultados dessa razão (E4/E6) juntamente aos coeficientes de $\Delta \operatorname{logK}$ para cada amostra de AH extraído, podem ainda ser organizados numa tabela em ordem decrescente dos graus de humificação [29]. Portanto, a Fig. 10 abaixo demonstra um modelo de espectro de UV-Vis acerca do $\mathrm{AH}$ para várias amostras, intituladas por: Tpa; Tpnc; Tph; Tpl; Tpm; Tpp; Tpg e Tpi de acordo com as localidades do estudo em questão. O destaque é visto nas intensidades dos espectros na faixa de 250-800 $\mathrm{nm}$ e suavemente um "ombro" na faixa de 270-280 nm do comprimento de onda (para todas as amostras). Esse resultado demonstra a presença de cromóforos no núcleo húmico e uma superposição de absorbância desses na região UV, podendo ser derivado de ácidos benzoicos, polieno, hidrocarbonetos, anilina, arenosos fenólicos e outros [29]. Ao que diz respeito a absorbância da luz visível, essa pode ter relação com estruturas quinoides, aromáticos policíclicos ou alifáticos e sistemas ceto-enol, desse modo apresentando complexos de metais e/ou intermoleculares ou intramoleculares, por exemplo [50].

Análise mineralógica utilizando DRX: Os resultados do ensaio de DRX são englobados em um difratograma que apresenta os picos correspondentes as distâncias interplanares (d) obtidas, essas últimas devem ser comparadas com as "d" típicas de cada fase mineral para então identificação. Os valores das d são definidas de acordo com a preparação da amostra, ou seja, se caso preparada apenas em condições normais, se acrescida de solvatação (ou glicolagem) e ainda aquecimento, tais procedimentos geram valores mais confiáveis conforme já citado no item C.2 (Análise mineralógica, metodologia) e observado na Tabela 1, que mostra os minerais possíveis de serem encontrados em argilas e suas correspondentes d em função da direção dos planos (no caso mostrado: o "001") [5]. Outros minerais não englobados na tabela acima também podem ser encontrados como quartzo ( $\mathrm{SiO} 2)$, Albita (NaAlSi3O8) e Siderite (FeCO3) em distâncias interplanares típicas (consideradas após solvatação e aquecimento): $3,34 \AA$ (direção 101) e 4,26 Å (direção 100); 3,19 A (direção 002) e $2,79 \AA$ (direção 104), respectivamente [41]. Dessa maneira, considerando um ensaio realizado com difratômetro do tipo Siemens modelo D 5000, com velocidade do goniômetro de $1 \%$ min, tubo de cobre $(\lambda=1,542 \AA)$ e com intervalo de varredura entre 2 a $15^{\circ}$ (escala $2 q)$, sendo a amostra preparada normal e com aquecimento à $500^{\circ} \mathrm{C}$ por $2 \mathrm{~h}$ [5]. Tem-se na fig.11 uma representação de um difratograma:

No estudo da figura acima, foram encontradas duas fases mineralógicas em uma amostra de argila, sendo elas a Ilita $((\mathrm{K}, \mathrm{H} 3 \mathrm{O})(\mathrm{Al}, \mathrm{Mg}, \mathrm{Fe}) 2(\mathrm{Si}, \mathrm{Al}) 4 \mathrm{O} 10[(\mathrm{OH}) 2,(\mathrm{H} 2 \mathrm{O})])$ (pico I) com maior dispersão e o quartzo (de fórmula química já citada) (pico Q), ambas referentes à direção (001) [5].

Tabela 2. Modelo de tabela comportando percentuais dos elementos químicos em uma amostra de argila após EDFRX, adaptada de [52]

\begin{tabular}{|c|c|c|c|c|c|c|}
\hline \multirow{3}{*}{$\begin{array}{l}\text { Amostra } \\
\text { Argila } \\
\text { Bentonítica }\end{array}$} & \multicolumn{5}{|c|}{$\begin{array}{l}\text { Percentuais dos elementos químicos na amostra } \\
\text { (\% massa) }\end{array}$} & \multirow[b]{2}{*}{$\mathrm{K} 2 \mathrm{O}$} \\
\hline & $\mathrm{SiO} 2$ & $\mathrm{~A} 12 \mathrm{O} 3$ & $\mathrm{Fe} 2 \mathrm{O} 3$ & $\mathrm{CaO}$ & $\mathrm{Na} 2 \mathrm{O}$ & \\
\hline & 60,46 & 16,53 & 8,44 & 0,98 & 0,31 & 0,28 \\
\hline & $\mathrm{MnO}$ & $\mathrm{TiO} 2$ & $\mathrm{MgO}$ & $\mathrm{P} 2 \mathrm{O} 5$ & P. Fogo & $\mathrm{Si} / \mathrm{Al}$ \\
\hline & 0,01 & 0,85 & 2,72 & 0,16 & 9,26 & 3,23 \\
\hline
\end{tabular}

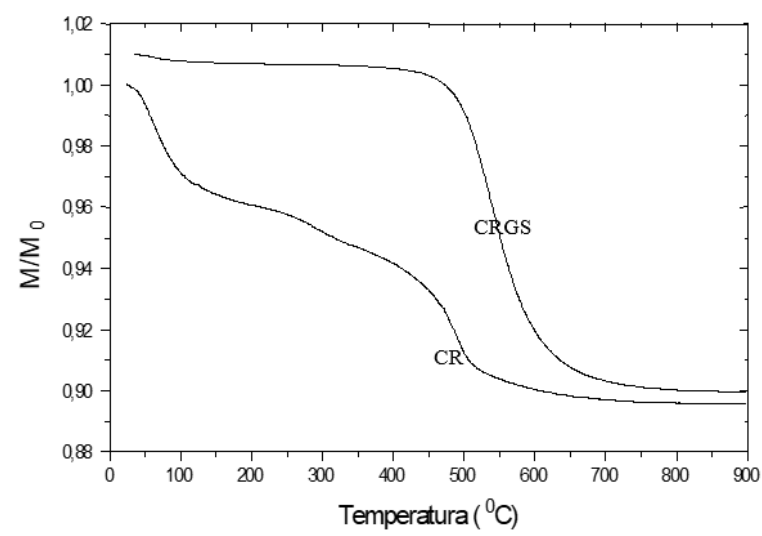

Fig. 13. Modelo de uma Curva TG em duas amostras de argila nomeadas de CR e CRGS (30 mg de cada amostra) [40].

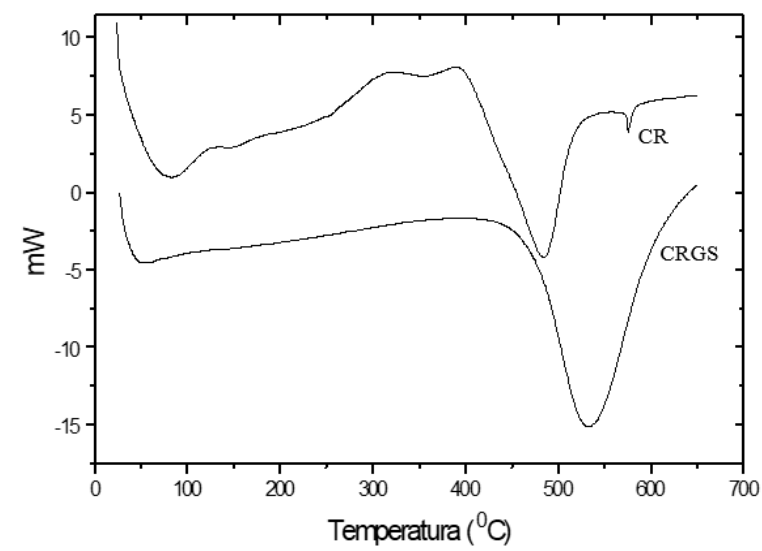

Fig. 14 Modelo de uma Curva DSC em duas amostras de argila nomeadas de CR e CRGS (30 mg de cada amostra) [40]

Análise química utilizando FRX: As análises de FRX em argilas como já citado, buscam convencionalmente os elementos químicos na forma de óxidos em porcentagem, são eles: $\mathrm{SiO} 2, \mathrm{~A} 12 \mathrm{O} 3, \mathrm{Cr} 2 \mathrm{O} 3$, $\mathrm{CaO}, \mathrm{MgO}, \mathrm{Na} 2 \mathrm{O}, \mathrm{TiO} 2, \mathrm{Fe} 2 \mathrm{O} 3, \mathrm{FeO}, \mathrm{P} 2 \mathrm{O} 5, \mathrm{MnO}, \mathrm{K} 2 \mathrm{O}, \mathrm{ZrO} 2$, $\mathrm{ZnO}, \mathrm{P} 2 \mathrm{O} 5, \mathrm{NiO}, \mathrm{Rb} 2 \mathrm{O}$ e outros [51]. Portanto, os resultados da espectroscopia do FRX são representadas em um gráfico com espectros de intensidade dos raios-X ou número médio de luminâncias recebidas pelo detector no decorrer do tempo da obtenção do sinal, normalmente em contagem por segundo (cps) no eixo das ordenadas (características de cada elemento), em função da energia emitida dada em Quilo elétron-Volt $(\mathrm{KeV})$ no eixo das abscissas em resposta à tensão da fonte de radiação [35]. Assim, considerando a técnica de EDFRX pelas maiores resolução e sensibilidade para altas energias $\mathrm{KeV}$, é demonstrado abaixo (Fig. 12) um espectro de uma argila tipo bentonítica [35], [52]. Vale ressaltar 
que os espectros podem sofrer algumas interferências dos constituintes da atmosfera (e gerar uma certa imprecisão na quantificação dos elementos mais leves), sendo indicado o ensaio numa atmosfera de hélio (gás de purga) utilizando um filtro Kapton, por exemplo [35]. Contudo, os resultados das intensidades dos picos podem ser interpretados através de meios estatísticos como a calibração multivariada por exemplo, que diminui erros por interferências espectrais na quantificação dos elementos. A partir disso, os quantitativos podem ser organizados em uma tabela com seus respectivos percentuais em peso da amostra [35]. Bem como mostrado na Tabela 2 em referência aos picos do modelo de espectros apresentado na Fig. 12, a tabela também comporta o percentual de perda ao fogo pelas pastilhas preparadas por fundição [52]. Percebese a predominância dos elementos dióxido de silício ( $\mathrm{SiO} 2)$ e óxido de alumínio (A12O3) na amostra do estudo em questão [52].

\begin{abstract}
Análises térmicas de TG E DSC: Os resultados da TG (termogravimétrica) e DSC (calorimetria exploratória) são interpretados por curvas em gráficos de Massa final/massa inicial (M/M0, eixo das ordenadas) versus temperatura em ${ }^{\circ} \mathrm{C}$ (eixo das abscissas) e de fluxo de calor (mVV, ordenadas) versus temperatura ${ }^{\circ} \mathrm{C}$ (abscissas), respectivamente. Desse modo, considerando a utilização de equipamentos Shimadzu TGA-50 e Shimadzu DSC-50 para realização das técnicas citadas, podem ser visualizados dois modelos de curvas de TG e DSC nas Fig. 13 e Fig.14, respectivamente [40]. Observou-se nessas curvas, uma reação do tipo endotérmica com perdas de massa e contração entre temperatura de $25^{\circ} \mathrm{C}$ e $130^{\circ} \mathrm{C}$ pela evaporação da água livre e já entre as temperaturas de $180^{\circ} \mathrm{C}$ e $400^{\circ} \mathrm{C}$ passam a acontecer respostas exotérmicas também com perda de massa, resultado de possíveis matérias orgânicas e sulfetos na amostra [40].
\end{abstract}

\section{CONCLUSÃO}

Portanto, conclui-se que são vastas as técnicas de caracterização de argilas e por sua vez também são vários os métodos de preparação das amostras. Dessa forma, buscou-se englobar aquelas de maior destaque e usabilidade pelas literaturas estudadas.

Agradecimentos: Agradecimentos ao PPGEM, seu corpo docente e à CAPES pela acessibilidade ao seu portal de periódicos.

\section{REFERÊNCIAS}

1. Vieira Coelho, A. C. P. D. S. Santos, and H. D. S. Santos, "Argilas especiais: O que são, caracterização e propriedades," Quim. Nova, vol. 30, no. 1, pp. 146-152, 2007, doi: 10.1590/S0100-40422007000100026.

2. Menezes, R. R. P. M. Souto, L. N. L. Santana, G. A. Neves, R. H. G. A. Kiminami, and H. C. Ferreira, "Argilas bentoníticas de Cubati, Paraíba, Brasil: Caracterização física-mineralógica," Cerâmica, vol. 55, no. 334, pp. 163-169, 2009, doi: 10.1590/s0366-69132009000200008.

3. Monsif M. et al., "Applied Clay Science Chemical-physical and mineralogical characterization of ceramic raw materials from Moroccan northern regions: Intriguing resources for industrial applications," Appl. Clay Sci., vol. 182, no. April, p. 105274, 2019, doi: 10.1016/j.clay.2019.105274.

4. Macedo, R. S. R. R. Menezes, G. A. Neves, H. C. Ferreira, U. Federal, and D. C. Grande, "Estudo de argilas usadas em cerâmica vermelha ( Study of clays used in red ceramic )," Cerâmica 54, vol. 54, pp. 411-417, 2008.

5. Albers, A. P. F. F. G. Melchiades, R. Machado, J. B. Baldo, and A. O. Boschi, "Um método simples de caracterização de argilominerais por difração de raios X," Cerâmica, vol. 48, no. 305, pp. 34-37, 2002, doi: 10.1590/s0366-69132002000100008.

6. Junior M. C. and L. C. Tanno, "C APÍTULO 33 Argila para Cerâmica Vermelha."
7. Sousa, J. P. "Caracterização tecnológica de argilas utilizadas na fabricação de cerâmica vermelha no múnicipio do crato - ceará.," Occup. Med. (Chic. Ill)., vol. 53, no. 4, p. 130, 2017.

8. Mahmoudi, S. A. Bennour, A. Meguebli, E. Srasra, and F. Zargouni, "Characterization and traditional ceramic application of clays from the Douiret region in South Tunisia," Appl. Clay Sci., vol. 127-128, pp. 78-87, 2016, doi: 10.1016/j.clay.2016.04.010.

9. Lahcen D. et al., "Characteristics and ceramic properties of clayey materials from Amezmiz region (Western High Atlas, Morocco)," Appl. Clay Sci., vol. 102, pp. 139-147, 2014, doi: 10.1016/j.clay.2014.09.029.

10. Monteiro, F. M. "Estudo das propriedades mineralógicas e tecnológicas de argilas da região do Agreste Potiguar para produção de cerâmica estrutural," Universidade Federal do Rio Grande do Norte, 2012.

11. ASSOCIAÇÃO BRASILEIRA DE NORMAS TÉCNICAS, "ABNT NBR 6457: AMOSTRAS DE SOLO - Preparação para ensaios de compactação e ensaios de caracterização." p. 9, 2016.

12. Comin, A. B. "Caracterização das argilas da formação rio bonito para aplicação industrial," Universidade Do Extremo Sul Catarinense - UNESC, 2018.

13. ASSOCIAÇÃO BRASILEIRA DE NORMAS TÉCNICAS, “ABNT NBR 7181: SOLOS - Análise Granulométrica,” p. 13, 1984.

14. Hernandez, G. M. C. H. P. Manual de métodos de análise de solo, $3^{\mathrm{a}}$. Brasília - DF: Revista e Ampliada, 2017.

15. ASSOCIAÇÃO BRASILEIRA DE NORMAS TÉCNICAS, “ABNT NBR 6459: Solo - Determinação Do Limite de Liquidez." p. 5, 2016.

16. ABNT NBR 7180: Solo — Determinação do limite de plasticidade." p. 3, 2016.

17. de Oliveira Modesto C. and A. M. Bernardin, "Determination of clay plasticity: Indentation method versus Pfefferkorn method," Appl. Clay Sci., vol. 40, no. 1-4, pp. 15-19, 2008, doi: 10.1016/j.clay.2007.06.007.

18. Ewane, M. S. V. Silvestri, and M. James, "Indentation of a Sensitive Clay by a Flat-Ended Axisymmetrical Punch," Geotech. Geol. Eng., vol. 36, no. 6, pp. 3601-3625, 2018, doi: 10.1007/s10706-018-0561-4.

19. Elyseu, F. "Desenvolvimento de cerâmica vermelha por monoqueima rápida a partir de massas compostas por argilominerais," Universidade Do Extremo Sul Catarinense UNESC, 2014.

20. ASSOCIAÇÃO BRASILEIRA DE NORMAS TÉCNICAS, “ABNT NBR 6502: Rochas e solos," p. 18, 1995.

21. Brunetto, G. G. W. Melo, J. Kaminski, V. Furlanetto, and F. B. Fialho, "Avaliação do método de perda de peso por ignição na análise de matéria orgânica em solos da Serra Gaúcha do Rio Grande do Sul," Ciência Rural, vol. 36, no. 6, pp. 1936-1939, 2006, doi: 10.1590/s0103-84782006000600045.

22. Silva N. and M. I. Astorga, "Textura, materia orgánica y composición química elemental $(\mathrm{C}$ y $\mathrm{N})$ de sedimentos marinos superficiales de la zona Puerto Montt a Boca del Guafo (Norpatagonia Chilena)," Lat. Am. J. Aquat. Res., vol. 38, no. 1, pp. 1-14, 2010, doi: 10.3856/vol38-issue1-fulltext-1.

23. Characterization, C. S. Of, S. Organic, F. Two, and S. Brazilian, "Chemical Characterization and Infrared Spectroscopy of Soil Organic Matter From Two Southern Brazilian Soils," Rev. Bras. Cienc. do Solo, vol. 27, no. 3, pp. 29-39, 2003.

24. Dobbss, L. B. V. M. Rumjaneck, M. A. Baldotto, A. C. X. Velloso, and L. P. Canellas, "Caracterização química e espectroscópica de ácidos húmicos e fúlvicos isolados da camada superficial de latossolos brasileiros," Rev. Bras. Ciência do Solo, vol. 33, no. 1, pp. 51-63, 2009, doi: 10.1590/s010006832009000100006.

25. Moreira, J. O. F. M. S., Siqueira, Microbiologia e Bioquímica do Solo, $2^{\mathrm{a}}$. Lavras, 2006.

26. Primo, D. C. R. S. C. Menezes, and T. O. Silva, "Substâncias húmicas da matéria orgânica do solo : uma revisão de técnicas analíticas e estudos no nordeste brasileiro," vol. 7, pp. 1-13, 2011. 
27. Canellas, L. P. Humosfera: tratado preliminar sobre a química das substâncias húmicas. 2005.

28. dos D. B. R. S. Silva, "Preparação e caracterização de nanofibras de polianilina/argila montmorilonita," Universidade Federal de Pernambuco - UFPE, 2018.

29. joão vitor silva de Loureiro, "Hca E Pca De Espectros Ft-Ir E UvVis De Ácidos Húmicos E Drx De Solos De Tpi," Universidade Federal do Amazonas, 2015.

30. Hernandez, G. M. C. H. P. "Capítulo 3: Análise Mineralógica das Frações Argila e Silte por Drifratometria de Raios-x," in Manual de Métodos de Análise de Solo, $3^{\mathrm{a}}$., Brasília - DF: Revista e Ampliada, 2017, pp. 452-471.

31. Skoog, T. A. D.A., Holler, F.J., Nieman, Princípios de Análise Instrumental. Porto Alegre: Bookman, 2002.

32. Senna, J. "Caracterização de Argilas de Utilização na Indústria Cerâmica por Espectroscopia de Reflectância," Universidade Estadual de Campinas, 2003.

33. Banaś D. et al., "Study of properties of chemically modified samples of halloysite mineral with X-ray fluorescence and X-ray powder diffraction methods," Radiat. Phys. Chem., vol. 93, pp. 129-134, 2013, doi: 10.1016/j.radphyschem.2013.05.028.

34. Silveira, R. G. G. C. L da; Sallet, "Caracterização físico-química de argilas do município de Itajá-RN para utilização em indústria cerâmica vermelha." Congresso Brasileiro de Engenharia e Ciência dos Materiais - CBECIMAT, Natal - Rio Grande do Norte, pp. 143-147, 2002.

35. Ascenso, R. C. "Fluorescência de raios-X no controlo da qualidade de amostras sólidas," Faculdade de Ciências e Tecnologia da Universidade de Coimbra, 2011.

36. Zorzi, J. E. S. G. Echeverregaray, J. V Emiliano, C. A. Perottoni, and R. C. D. Cruz, "Caracterização de matérias-primas cerâmicas do Vale do Rio Caí Characterization of ceramic raw materials from the Caí River Valley, RS, Brazil," Cerâmica, vol. 58, no. 348, pp. 509-515, 2012.

37. de C. M. O. Prado, "Caracterização Química e Mineralógica das Argilas Utilizadas na Produção de Cerâmica Vermelha no Estado de Sergipe," Universidade Federal de Sergipe, 2011.

38. da R. M. C. e; Silva, V. F. do; Nascimento Filho, and C. R. Appoloni, "Fluorescência de raios-X por dispersão em energia," LFNATEC Publicação Técnica do Laboratório Física Nucl. Apl., vol. 08, no. 2178-4507, p. 19, 2004.

39. U. S. A et al., "Lithos Timing and duration of the Central Atlantic magmatic province in the Newark and," LITHOS, vol. 122, no. 34, pp. 175-188, 2011, doi: 10.1016/j.lithos.2010.12.013.

40. Maia, L. J. Q. T. A. Martins, A. L. D. Gesicki, and A. R. Salvetti, "Caracterização térmica de argilas da cidade de Costa Rica no estado de Mato Grosso do Sul," Anais do $44^{\circ}$ Congresso Brasileiro de Cerâmica, São Pedro - SP, pp. 101-110, 2000.
41. Oikonomopoulos, I. K. M. Perraki, N. Tougiannidis, T. Perraki, H. U. Kasper, and M. Gurk, "Clays from Neogene Achlada lignite deposits in Florina basin (Western Macedonia, N. Greece): A prospective resource for the ceramics industry," Appl. Clay Sci., vol. 103, pp. 1-9, 2015, doi: 10.1016/j.clay.2014.11.002.

42. Alves, A. L. A. A. Ferreira, A. A. Zanfolim, E. S. Saraiva, and A. R. Salvetti, "Caracterização térmica da argila de Angélica/MS," Anais $48^{\circ}$ Congresso Brasileiro de Cerâmica, Curitiba-PR, pp. 149-150, 2004

43. Denari G. B. and E. T. G. Cavalheiro, "Princípios e aplicações de Análise Térmica," in Journal of Poultry Science, São Carlos - SP: IQSC, 2012, p. 40.

44. Barbosa, R. E. M. Araújo, T. J. A. de Melo, and E. N. Ito, "Preparação de argilas organofilicas e desenvolvimento de nanocompósitos de polietileno. Parte 2: comportamento de inflamabilidade," Polímeros, vol. 17, no. 2, pp. 104-112, 2007, doi: 10.1590/s0104-14282007000200009.

45. Santos, C. P. H. A. Oliveira, R. M. P. B. Oliveira, and Z. S. Macedo, "Caracterização de argilas calcárias utilizadas na produção de revestimentos cerâmicos no Estado de SergipeBrasil," Ceramica, vol. 62, no. 362, pp. 147-156, 2016, doi: 10.1590/0366-69132016623621983.

46. dos Santos, R. D. R. C. de Lemos, H. G. dos Santos, J. C. Ker, and L. H. C. dos Anjos, Manual de descrição e coleta de solo no campo, $5^{\text {a }}$. Viçosa - CE: Revista e Ampliada, 2005.

47. Caputo, H. P. "Mecânica dos Solos e suas Aplicações," Mecânica dos Solos e suas Apl., p. 244, 1988, [Online]. Available:

https://engenhariacivilfsp.files.wordpress.com/2015/05/mecanicasolos-fundamentos-vol1-6ed-caputo.pdf.

48. Bayer, C. L. Martin-Neto, J. Mielniczuk, S. D. C. Saab, D. M. P. Milori, and V. S. Bagnato, "Tillage and cropping system effects on soil humic acid characteristics as determined by electron spin resonance and fluorescence spectroscopies," Geoderma, vol. 105, no. 1-2, pp. 81-92, 2002, doi: 10.1016/S0016-7061(01)00093-3.

49. Senesi, N. V. D'Orazio, and G. Ricca, "Humic acids in the first generation of EUROSOILS," Geoderma, vol. 116, no. 3-4, pp. 325-344, 2003, doi: 10.1016/S0016-7061(03)00107-1.

50. De Azevedo J. C. R. and J. Nozaki, “Análise de fluorescência de substâncias húmicas extraídas da água, solo e sedimento da Lagoa dos Patos - MS," Quim. Nova, vol. 31, no. 6, pp. 1324-1329, 2008, doi: 10.1590/S0100-40422008000600010.

51. Bain, D. C. W. J. McHardy, and E. E. Lachowski, "X-ray fluorescence spectroscopy and microanalysis," in Clay Mineralogy: Spectroscopic and Chemical Determinative Methods, 1994, pp. 260-299.

52. Rodrigues, M. G. F. M. L. P. Silva, and M. G. C. da Silva, "Caracterização da argila bentonítica para utilização na remoção de chumbo de efluentes sintéticos," Cerâmica, vol. 50, no. 315, pp. 190-196, 2004, doi: 10.1590/s0366-69132004000300004. 